\title{
SUSTAINING INNOVATIONS COMMUNITY HEALTH OUTPOST (POSYANDU) - LESSONS LEARNT
}

\author{
Ravi K. Menon \\ Global Alliance for Improved Nutrition (GAIN) Based In Geneva, Switzerland \\ rmenon@gainhealth.org
}

\begin{abstract}
GAIN, in partnership with Indonesia's Ministry of Health's Directorate of Community Nutrition, embarked on a 6 year program called BADUTA 2014 - 2020 to supports the 1000 Days of Life Program Impact Pathway and to improve sustainability community health in East Java. One major component of the program is a behaviour change campaign called Rumpi Sehat (Health Gossip) and community activation designed to provoke an emotional response called "Emo-Demo's" (emotional demonstrations). GAIN's team worked with the London School of Hygiene and Tropical Medicine to develop the TV commercials and the Emo Demo's. These activities include fun games, which are engaging and motivating mothers to participate and giving them the confidence to practice the right feeding behaviors. Also engaged the parents in an 'emo demo', routinely practiced at the health center, to trigger the disgust factor when dissolving these packaged snack foods in water (mimicking the stomach). GAIN and its partners have been documenting the significant changes triggered by the Rumpi Sehat campaign and Emo - Demos Snacking, which are best practice examples of women who have taken action within their communities and advocating for better nutrition. Selected program result in 2017 , are $6 \%$ increase of children $6-23$ months of age consuming minimum number of food groups associated with nutrient adequacy, $12 \%$ increase of children $6-23$ months of age consuming iron-rich foods, and $15 \%$ increase mothers of infants $<6$ months of age who report exclusive breastfeeding.
\end{abstract}

Keywords: GAIN, BADUTA, Rumpi Sehat, Emo - Demo

\section{INTRODUCTION}

The "first 1,000 days" of life - from conception to a child's second birthday — is a critical window of opportunity for optimizing the nutritional, health, and development outcomes of current and future generations. The nutritional status of a woman at conception and during pregnancy, along with nutrition during the child's first 2 years of life, affect the short- and long-term health of her offspring, including long-term chronic disease outcomes (FANTA). Once born, children have high nutritional needs for the first 2 years of life because of their rapid physical growth and cognitive development (FANTA).

Global Alliance for Improved Nutrition (GAIN) created within the UN in 2002 during the Special Session of the UN General Assembly on Children, and redesigned as a Swiss foundation in 2005. GAIN's vision is driven by the vision of a world without malnutrition. GAIN's mission is to improve the consumption of nutritious and safe food for all people and particularly populations at risk such as women and children. GAIN Organizational objectives are to strengthen the enabling environment to improve the consumption of safe, nutritious foods; to improve the demand for safe, nutritious foods; and to increase the availability and affordability of safe, nutritious foods. GAIN Indonesia was registered in 2014 and has an ongoing MOU with MOH (Kemenkes).

\section{THEORITICAL FRAMEWORK}

Community-based health promotion and preventive health care services are significant in addressing health disparities and expanding access to health care services in rural communities (Campbell, 2007). Over the years, such projects have been implemented in different community settings to address many health issues in rural communities because experts believe that they are very effective in delivering meaningful grass root health care services to rural populations (Brownson, 1996). Their 
benefits are highlighted by abundance of grant-funding opportunities available from many government agencies and programs and numerous private organizations and foundations for different kinds of health and wellness programs that utilize community-based strategies. However, in spite of their notable benefits, sustainability continues to be a major challenge for grantees and grantors (Emekalam, 2012). Additionally, sustained programs translate into sustained effects over time thereby making proper evaluation of longterm effects and assessments of programs possible (Puska, 1996; Manfredi, 2001).

Posyandu is Family Planning Services - Integrated Health Services, basic health activities organized from, by, and for communities assisted by health workers. Posyandu is one of the Community Resource Health Efforts (UKBM). So, Posyandu is a self-help activity from the community in the health sector with the person in charge of the village head. Posyandu starts primarily to serve toddlers (immunization, weight gain) and the elderly (Posyandu Lansia), and is born through a Joint Decree between the Indonesian Minister of Home Affairs (Minister of Home Affairs), Minister of Health (Menkes) RI, Head of the Family Planning Coordinating Board National (BKKBN) and Chair of the Family Welfare Development Team (TP) and was launched around 1986. According to the Ministry of Health the purpose of the Posyandu is to speed up the reduction in infant, under-five and birth rates, speed up NKKBS acceptance, and improve the ability of the community to develop health and other supporting activities, as needed (Wikipedia).

In 2013, GAIN, in partnership with Indonesia's Ministry of Health's Directorate of Community Nutrition, embarked on a 4 year program called BADUTA to improve the feeding practices of pregnant mothers and children under the age of two years, in six sub districts of Sidoarjo and Malang in East Java. The program is currently being implemented in 113 villages in Sidoarjo and Malang, with partners Save the Children, Yayasan Paramitra, \& PT Holland for Water (www.gainhealth.org).

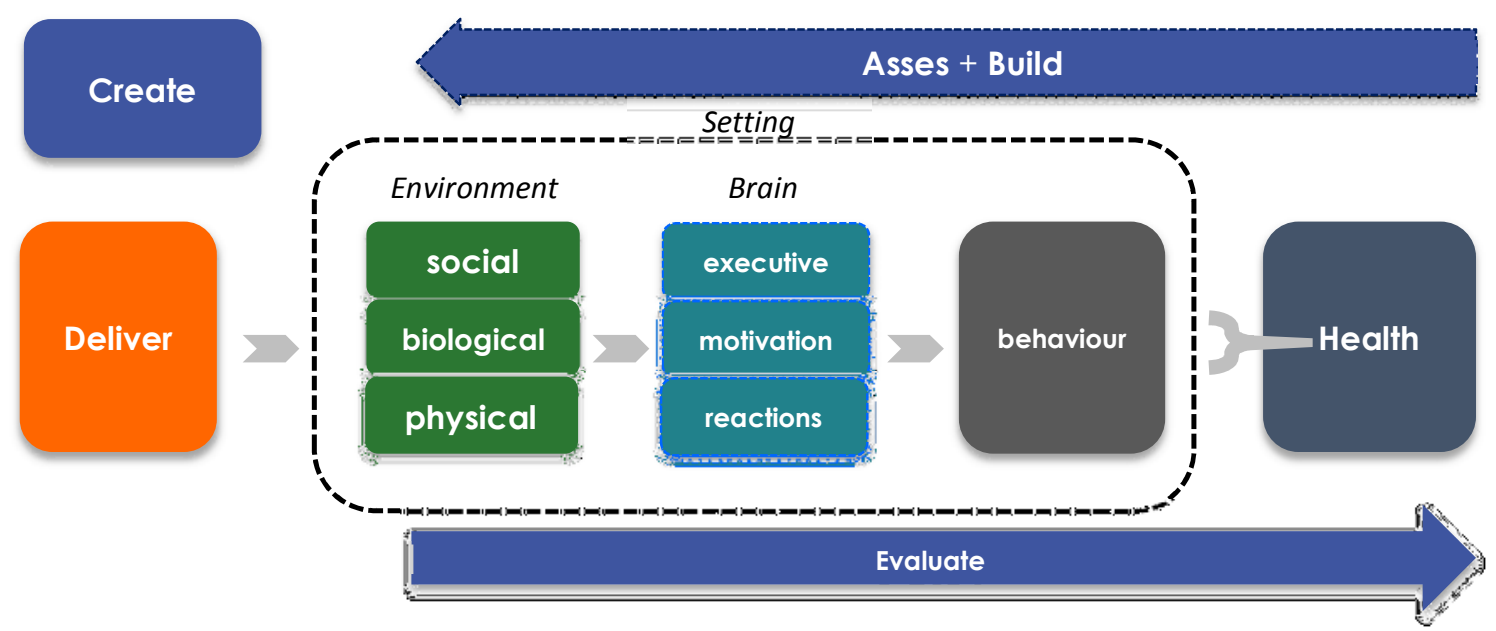

Figure 1. SBCC campaign used the Behavior-centered design

For the development of the BCI component, GAIN worked very closely with behavior experts from the London School of Hygiene and Tropical Medicine, whose theoretical model has its roots in evolutionary biology and ecological psychology. They call it Behaviour Centred Design (Curtis \& Aunger). The model is based on the inference that behaviour (the grey box) is produced by brains (the blue box), and that it evolves to provide adaptive responses to rapidly changing or complex environmental conditions (the green box) (Figure 1).

\section{METHODS}

\section{Rumpi Sehat - Campaign}

The idea for the slogan was based on the insight that gossip is part of daily life and based on observations that mothers and caregivers were constantly feeling judged by their social circle and their desire to be seen as a good mother/caregiver. 
Key principles of the campaign, are use realistic situations and avoid health jargon, use comedy and catchy gestures, strong visual cues, represent desired behaviour as the social norm, and 'A-Ha' moment.

Based on the FR several umbrella campaign ideas were developed and tested. The insights that social judgement of mothers is omnipresent, and that Indonesians love to engage in 'gossip' (there are even gossip soaps on TV), led to the birth of the campaign idea of Healthy Gossip. This campaign idea is the 'brand' under which all SBCC activities are executed. Other behavior changes principles that have been applied in all executions, and which tap into emotional or underlying motives include:

a. Using real-life situations, the same real-life key characters, and avoiding public health jargon as much as possible.

b. Using a number of repeated, recognizable elements and a good dose of humor such as the gesture of pushing away bad behavior, the revelation moment when Lady Gossip gets corrected by a head slap.

c. Using a lot of visual cues instead of speech, as this is stronger and sticks to the mind.

d. by presenting the good behavior as one that everyone knows about - except Lady Gossip - we aim at creating a social norm, and a social movement.

Four key messages have been prioritised based on formative research (Figure 2). The selection of these messages has been validated with experts at the national level and approved by the Directorate of Nutrition of Ministry of Health. The TV commercials focus on these four messages alone. The community activation elaborates with supportive messages for each of those four keys. More detailed messages as per Ministry of Health guidance are provided at the health center by interpersonal communication.
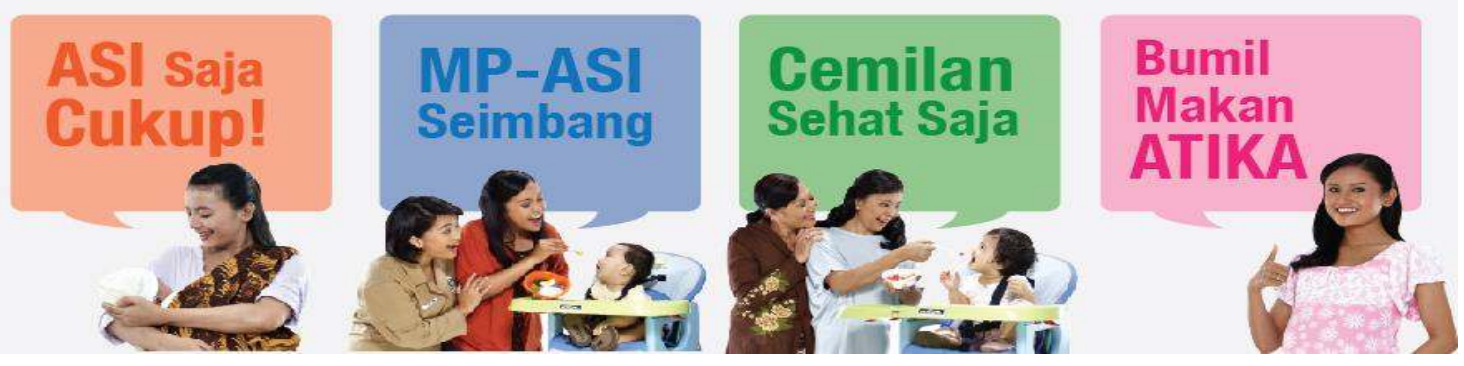

Figure 2. Four Key Messages

\section{Emotional - Demonstration (Emo - Demo) Snacking}

Emotional - Demonstration are a technique developed by London School of Hygiene and Tropical Medicine (LSHTM). Succesfully used for handwashing with soap but were not tested for nutrition. GAIN and LSHTM spent 6 months designing, testing, and finishing twelve Emo - Demos to be used for the community level activationof the Rumpi Sehat Campaign. Every Emo - Demo was developed based on the Evo - Eco theory. Principles of Emo - Demos are simple to conduct, real situations, emotional response, surprising, social / participative, and instructive (Figure 3).

Most typical insights of giving her children snack is mothers want quiet children because crying kids would signify that she is a bad mom. She achieves this by permitting the child to eat snacks at all times. They do not understand that this behaviour actually fills the child's stomach and results in eating less of the healthier meals.

From Figure 4, the visual pushing away of the hand that tries to give a crisp to a child is perceived as a very strong gesture in Indonesia. It translated into an emo-demo by making mothers feel "disgusted", by dissolving puffed colored snacks in water and asking mothers to drink it - create a disgust factor. Furthermore through the game of bucket and balls, we demonstrate that snacking prior to mealtime, fills baby's tummy. 


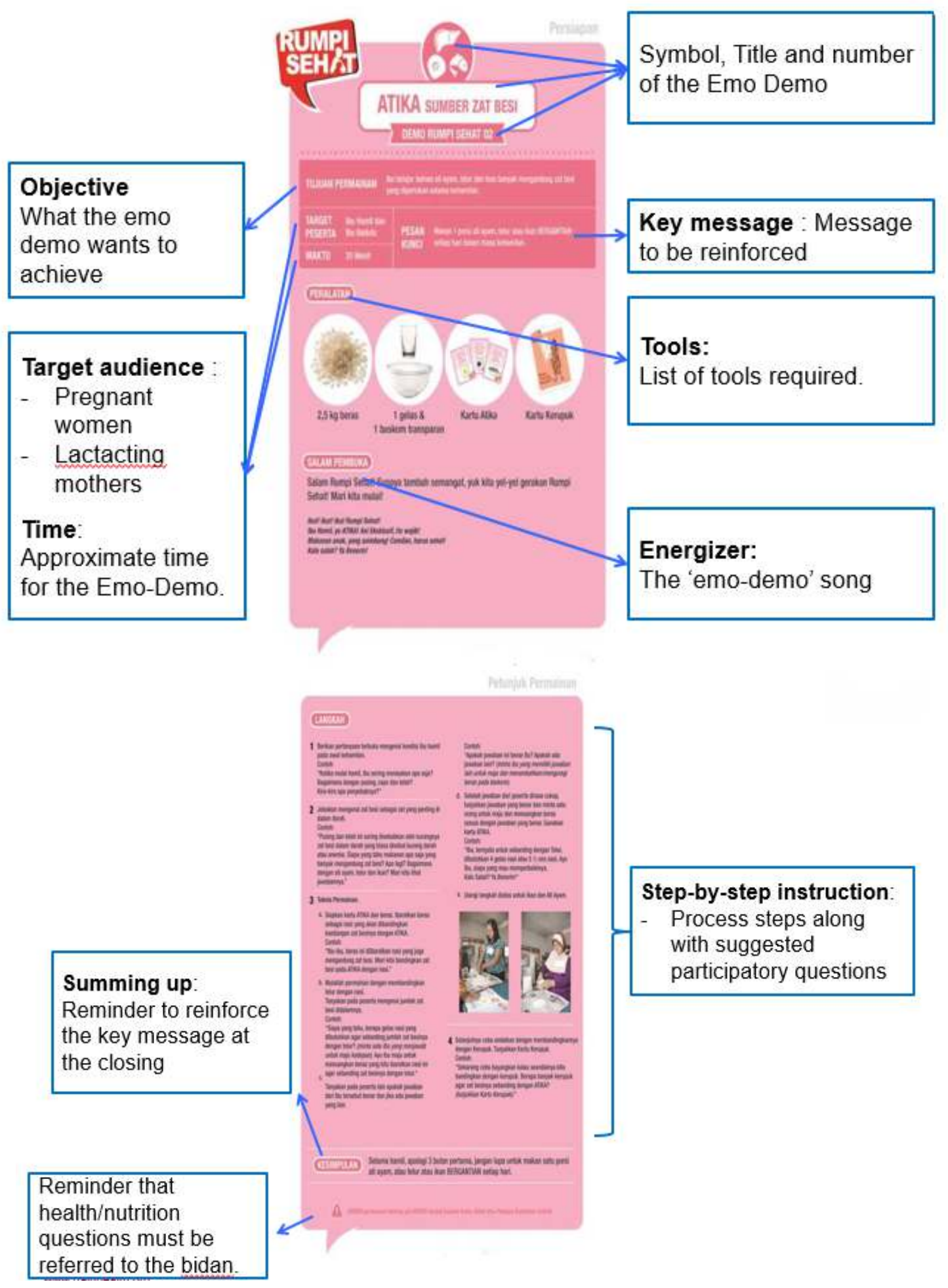

Figure 3. Emo - Demo visual aid Module 


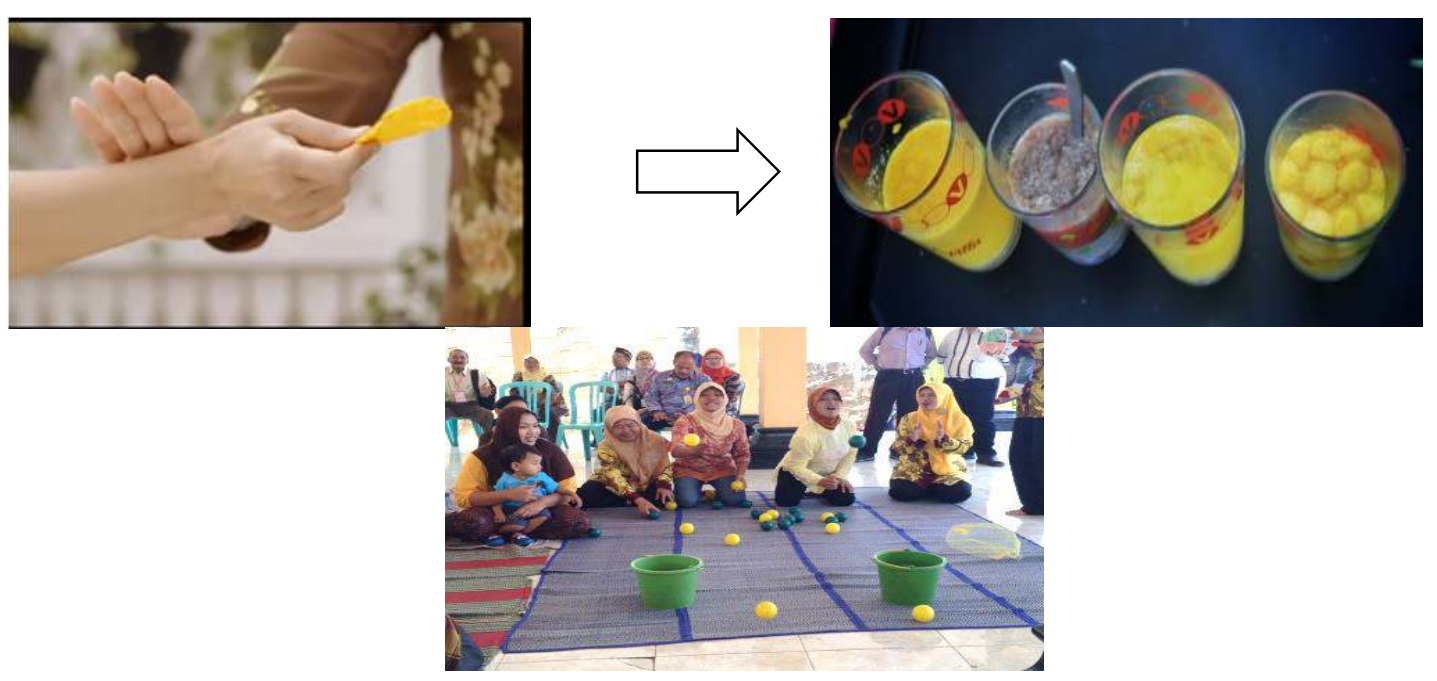

Figure 4. The TVC visual translated into an emo-demo, and game of bucket and balls

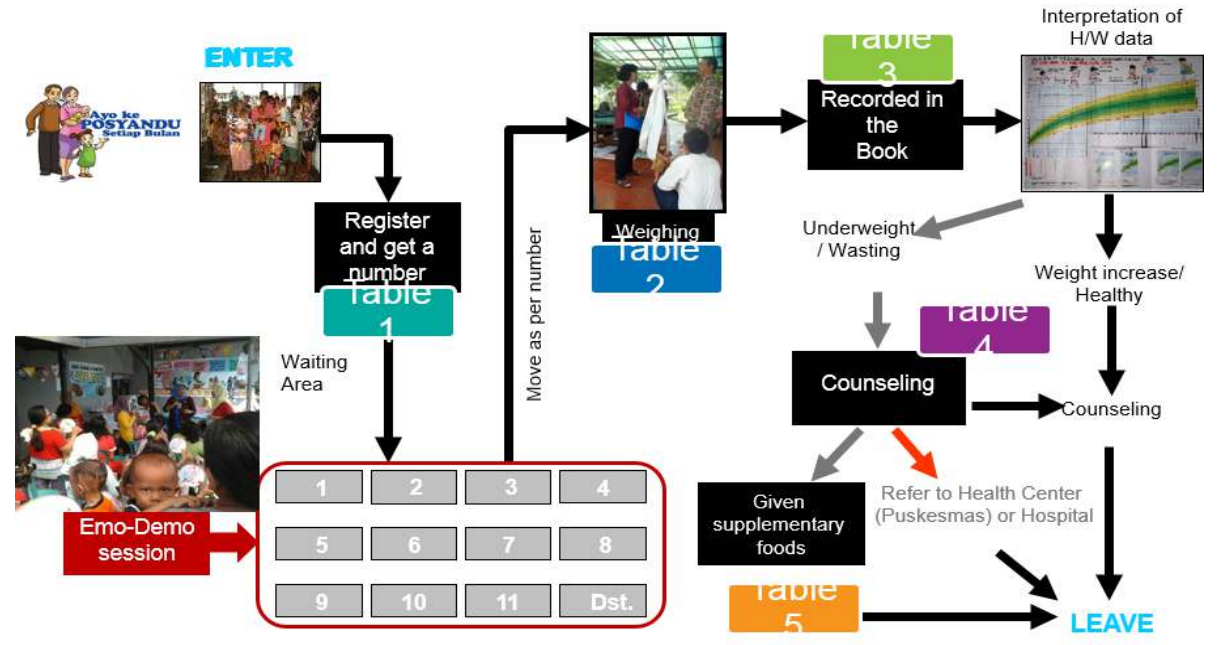

Figure 5. Integration of emo-demos at Posyandu

\section{RESULT AND DISCUSSION}

In Phase 1, 2015-2017 "Emo Demo" were held in 113 villages in Sidoarjo dan Malang at 689 Posyandus and Kelas Ibu's accompanied by 18 months TV campaign.
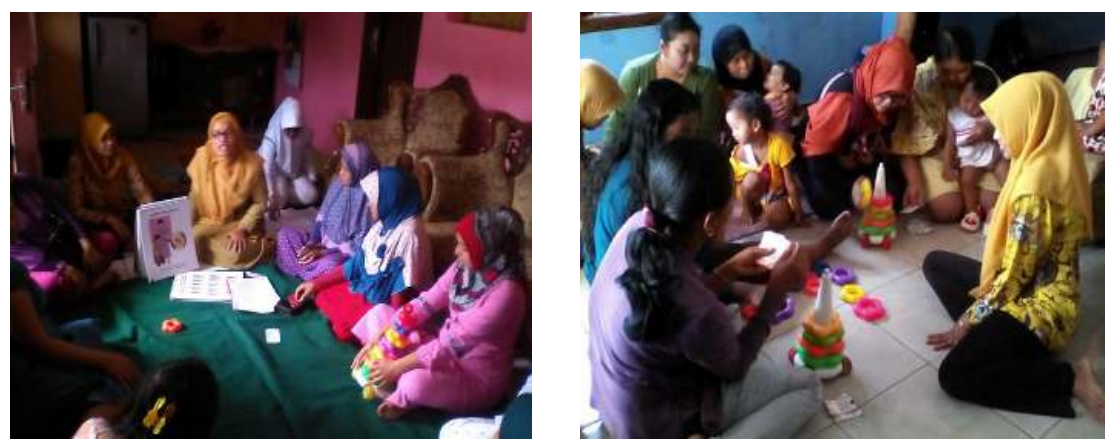

Figure 6. Posyandu and Kelas Ibu activation 
Selected Program Results in 2017

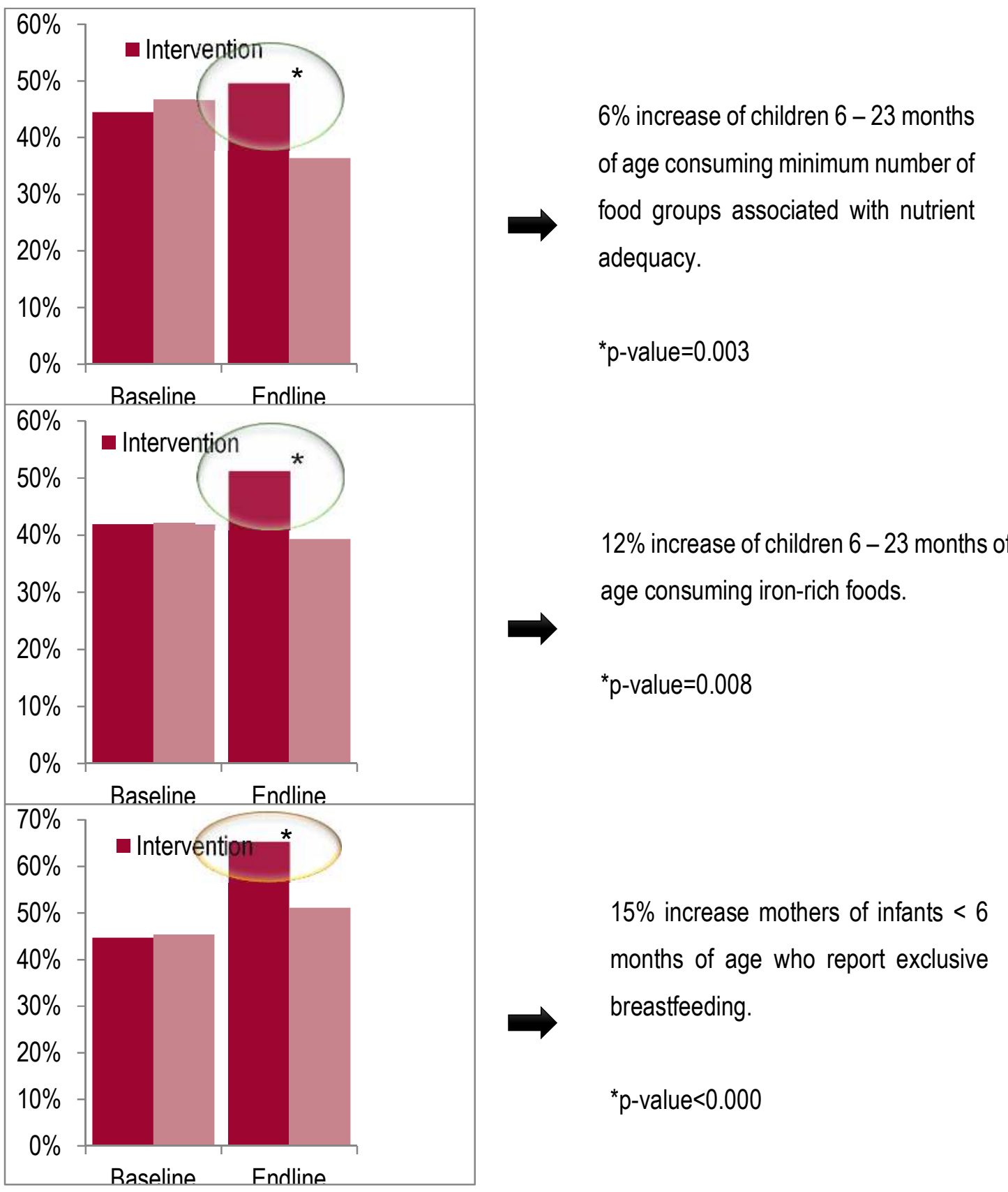

Approached subjects to ensure sustainability, are:

1. Caregivers, mothers and kaders (who are mothers too) so that they would demand continuation of the service

2. Puskesmas and Village heads so that they would budget for the activity

3. Academics in the nutrition field, so that they would provide an endorsement to policymakers, adopt the curricula and develop new emo-demos.

4. Policy-makers (DHO, PHO) so that they would change the guideline based on testimony from above three stakeholders

5. Donor to obtain additional funding for scale-up 
In November 2017, East Java Provincial Government adopted emo-demos for improving IYCF practices into the Taman Posyandu Guideline (Figure 7), through:

1. Series of adoption workshops with multi-stakeholders

2. Inserting and pre-testing emo-demo modules into the guideline.

3. Promoting to district/city leaders

4. Providing access to fund and technical assistance for initial implementation
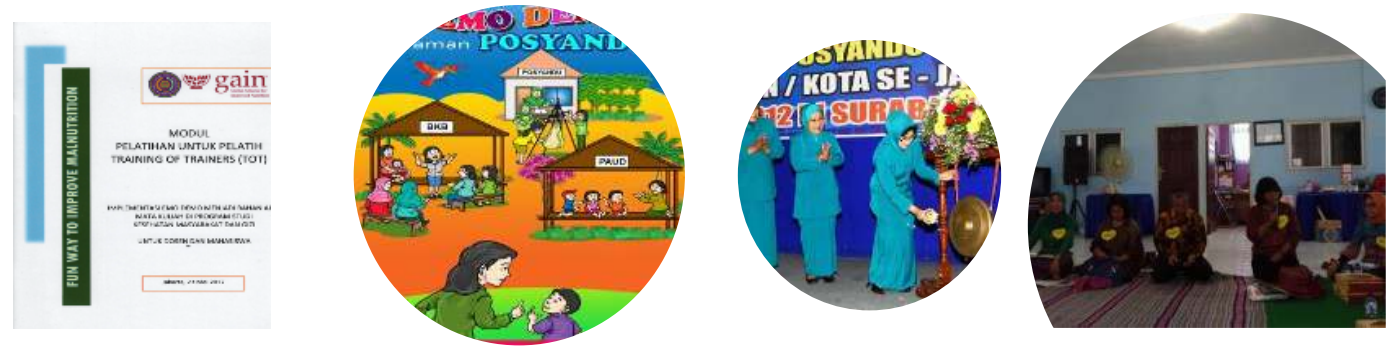

Figure 7. Adoption into Taman Posyandu guidelines

Starting 2018, 15 universities and institutions (10 in and 5 outside East Java) adopted emodemos as teaching materials (Figure 8), through:

1. The formation of drafting teams

2. Introduction and workshops on Emo Demo materials

3. Development of syllabus, handouts/teaching materials/modules (ToT)

4. Testing developed materials to lecturers and students

5. ToT/Debriefing for lecturers and students

6. Implementation of Emo Demo materials by lecturers in class

7. Implementation of Emo Demo materials by lecturers/students in targeted regions
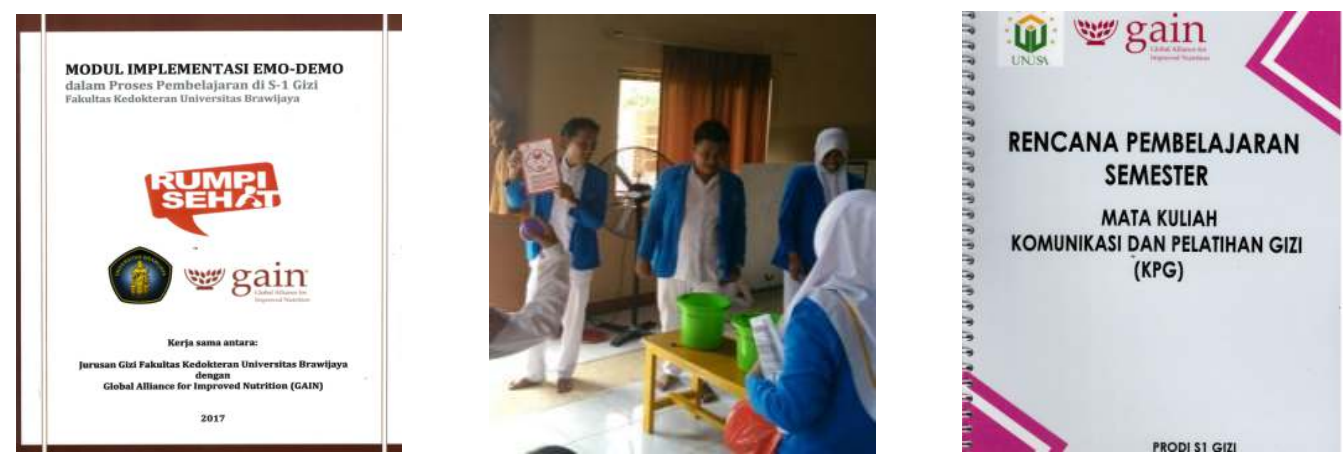

Figure 8. Integration of Emo-Demos into curricula

At posyandu level, emo-demos proved an innovative method of helping cadre and midwives to promote nutritional behavior change. However, we found that the modules needed to be simplified, content expanded to other topics and timing of topics better aligned with the developmental stage of the child. At health system level, broader governance and capacity issues (i.e. involving village heads and health centres) were key in seeking support for cadres and financing related programs. At inter-sectoral level, enabling universities to adopt the module as teaching material would ensure sufficient technical support for emo-demo activities. Since posyandu is a community-based, village-level program, crosssector support - particularly from the higher education sector is needed.

In phase 2, 2018-2020 they are being scaled up 512 villages (50\%) in Probolinggo, Bondowoso, Jember, Treggalek and Surabaya covering 3000 posyandus. The remaining $50 \%$ of the villages and additional 31 districts in East Java have been allocated budgets to introduce the emo-demo methodology by the PHO and DHO. The key to the scaling up is the MOT and TOT program. As of 31 Oct 2018, 
1,448 people have received ToT as Emo-demo trainers in the 5 targeted districts, and 146 people outside the targeted areas in 3 other provinces.

\section{CONCLUSION}

Based on the result, BADUTA program to supports the 1000 Days of Life Program Impact Pathway in East Java has a significant impact on improved nutrition in the first 1000 days of life. The most significant changes triggered by the Rumpi Sehat campaign and Emo - Demos. Program result in 2017 , are $6 \%$ increase of children $6-23$ months of age consuming minimum number of food groups associated with nutrient adequacy, $12 \%$ increase of children $6-23$ months of age consuming iron-rich foods, and $15 \%$ increase mothers of infants $<6$ months of age who report exclusive breastfeeding.

\section{REFERENCES}

Brownson RC, Smith CA, Pratt M, Mack NE, Jackson-Thompson J, et al. 1996. Preventing cardiovascular disease through community-based risk reduction: Bootheel Heart Health Project. Am J Public Health 86: 206-213.

Campbell MK, Hudson MA, Resnicow K, Blakeney N, Paxton A, et al. (2007) Church based health promotion interventions: evidence and lessons learned. Annu Rev Public Health 28: 213-234.

Emekalam, A. U. 2012. A Conceptual Sustainability Strategy for a Rurally-Based Community Health Promotion Initiative. J Health and Med Informat Volume 3: $1-6$

Food and Nutrition Technical Assistance III Project (FANTA). Strengthening The Evidence Base for Nutrition Interventions During The "1,000 DAYS": FANTA Research Explores How to Optimize the Prevention of Malnutrition. USAID. Washington DC.

https://id.wikipedia.org/wiki/Pos_Pelayanan_Terpadu [21/11/2018 22:00]

https://www.gainhealth.org/knowledge-centre/category/country/indonesia/ [21/11/2018 22:00]

https://www.gainhealth.org/knowledge-centre/inspiring-indonesian-mothers-change-eating-feedingpractices/ [21/11/2018 22:00]

Manfredi C, Crittenden K, Cho YI, Engler J, Warnecke R (2001) Maintenance of a smoking cessation program in public health clinics beyond the experimental evaluation period. Public Health Rep 116: $120-135$.

Puska P, Nissinen A, Toumilehto J, Salonen JT, Koskela K, et al. (1996) The community-based strategy to prevent coronary heart disease: conclusions from the ten years of the North Karelia project in PAN American Health Organization (Ed.), Health promotion: An anthology. Washington pan American Health Organization 89-125.

https://www.bappenas.go.id/id/profil-bappenas/unit-kerja/deputi-sdm/dit-kgm/contents-direktoratkesehatan-dan-gizi-masyarakat/gerakan-nasional-percepatan-perbaikan-gizi/

https://www.unicef-irc.org/article/958-the-first-1000-days-of-life-the-brains-window-ofopportunity.html

https://www.ncbi.nlm.nih.gov/pmc/articles/PMC5214166/

https://www.youtube.com/channel/UCIKOLV7zeeYKT2LQrtMtDaA

https://www.youtube.com/watch?v=VsEH7SpwKc8 